\title{
The Task-Based Syllabus: Promoting L2 Acquisition and Learner Empowerment in an EFL Classroom
}

\author{
Gabriella Torres ${ }^{1, *}$ \\ ${ }^{1}$ Hankuk University of Foreign Studies, 89 Wangsan-ri, Mohyeon-myeon, Choin-gu, \\ Yongin-si, Gyeonggi-do, South Korea \\ *Correspondence: Tel: 82-31-330-4030 E-mail: gstorres@gmail.com
}

Received: March 6, 2014

doi:10.5296/ije.v6i2.5254
Accepted: March 24, 2014 Published: April 26, 2014

URL: http://dx.doi.org/10.5296/ije.v6i2.5254

\begin{abstract}
The purpose of this paper is to illustrate how the Task-Based Syllabus (TBS) can be used to promote L2 acquisition and learner empowerment in an English as a Foreign Language (EFL) context. The paper begins by reviewing definitions of the Task-Based Syllabus as well as the term "task" in relation to the syllabus. It then examines influential theories, which have helped shape the Task-Based Syllabus before identifying its strengths and weaknesses in the classroom. The author then identifies ideal teaching situations for implementing a Task-Based Syllabus in order to encourage L2 acquisition and facilitate learner motivation and empowerment by promoting language learning strategy awareness.
\end{abstract}

Keywords: Task-based syllabus (TBS), task-based learning (TBL), second language acquisition (SLA), learner empowerment 


\section{Introduction}

Though significant developments have been made in our understanding of L2 learning and acquisition, language teaching is still an area of much frustration for both teachers and learners alike. Educators are often left to wonder, "Why don't learners learn what teachers teach?” (Allwrite 1984, cited in Nunan 1999:11) while learners often associate their experience of language learning with relative failure (Skehan 1996b: 18), unable to effectively communicate using the L2 they have studied (Willis 1996b: 5).

In response to this, SLA researchers have proposed a task-based syllabus as a viable solution to many of the problems found in the arena of language learning and teaching. By using task as a unit of analysis, the task-based syllabus (TBS) proposes a more holistic approach to L2 learning and acquisition (Willis 1996a: 52), in which meaning is primary and assessment is outcome-based (Skehan 1996a: 38).

The purpose of this paper is to first provide a definition of the task-based syllabus and the task. The author will then consider the development of TBS and show how it has been influenced by certain theories of language and learning before identifying its strengths and weaknesses. The writer will then proceed to argue that despite these weaknesses, TBS still remains the most promising syllabus for L2 acquisition and learner empowerment in the classroom.

\section{The Task-Based Syllabus: Definitions}

Before proceeding, it is important for the purposes of this paper to first define the task-based syllabus (TBS) and the task before identifying the theories of language and learning that have influenced it.

\subsection{Definition of Task-Based Syllabus}

TBS can be classified as an analytic, process-based procedural syllabus that is primarily Type B in nature in which what is learned is subordinate to how it is learned (White 1988: 46, Long \& Crookes 1992: 29). It represents a departure from the traditional Type A, synthetic or product oriented syllabus common to many language-learning contexts (Long \& Crookes 1992; Skehan 1996a). Unlike these syllabus types, which use linguistic elements (such as word, structure, notion or function) as the unit of design, TBS opts instead to use "some conception of task" (Long \& Crookes 1992: 27) as the unit around which the course is organized. These units, according to Littlewood, "provide a link between outside-classroom reality [target tasks] and inside-classroom pedagogy [pedagogical tasks]” (2004: 324). With task as its point of departure, TBS focuses not on "particular words or grammar rules the learner will need to acquire, but rather...the purposes for which people are learning a language, i.e. the tasks that learners will need to be able to perform” (Van den Branden 2006: 3). 


\subsection{Task}

The "conception of task", as stated by Long (see 2.1), varies throughout the SLA literature. However, as Richards and Rodgers points out, "there is a commonsensical understanding that a task is an activity that is carried out using language" (2001: 224). For example, as per Willis, a task is "a goal-oriented activity in which learners use language to achieve a real outcome” (1996a: 53). Skehan defines task as "an activity in which meaning is primary, there is some sort of relationship to the real world, task completion has some priority and the assessment of task performance is in terms of task outcome” (1996b: 38). Although variations exist, most definitions emphasize that tasks are activities (things people do); they are goal-directed and necessitate the use of language for performance and goal achievement (Van den Branden 2006: 3).

Tasks in relation to TBS can be divided into two types: the target task and the pedagogic task. The target task refers to tasks, which are 'real-world' in nature or exist outside of the classroom setting. They are derived from an analysis of why learners are learning a second language and the functional things they want or need to use the language for (Van den Bradnen 2006: 12). Pedagogic tasks, on the other hand, are classroom tasks that set demands in order to promote learning (Bygate 1999: 34). They provide a vehicle for the presentation of appropriate target language to learners who, through the application of cognitive processing capacities, reshape the target samples for the delivery of comprehension and production (Long \& Crookes 1992: 43).

\section{The Task-Based Syllabus: Influential Theories}

Before identifying the strengths and weaknesses of TBS, the paper will first examine theories of language and learning that have proved influential to TBS.

\subsection{Language Theory: Meaning is Primary}

During the 1970s, a much more dynamic understanding of language began to emerge in the field of ELT (Nunan 1999: 9). Meaning was now at the forefront of language teaching and learning, which was reflected in the various realizations of communicative language teaching (CLT) that developed as a result. Task-based language teaching (TBLT) and TBS are no exception to this.

TBLT and TBS "takes meaning as its starting point" (Willis \& Willis 2007: 177) and holds that through engaging in meaning, learners' language systems are encouraged to develop (Skehan 1996a: 20). This primacy of meaning is further supported through the assessment of tasks, which is based on the nonlinguistic outcomes of task completion (Skehan 1996b; Nunan 1999). In this regard, tasks necessitate the meaningful exchange of language for a real purpose: task completion (Willis 1996a: 54). Language becomes a means to an end for achieving task outcome (a result of meaning exchange) rather than the end itself. In other words, TBLT and TBS are not “concerned with language display” (Skehan 1998: 98, cited in Richards and Rodgers 2001: 226). 


\subsection{Learning Theory: CLT Principles}

As previously discussed (See 3.1), TBLT and TBS developed out of CLT and one can see how certain of the CLT principles have informed the notion and function of the task within the TBS framework. According the Richards and Rodgers (2001: 223), TBLT has drawn on the following principles of CLT:

- Activities that involve real communication are essential for language learning.

- Activities in which language is used for carrying out meaningful tasks promote learning.

- Language that is meaningful to the learner supports the learning process.

To some extent, these principles can be seen as the foundation from which the concept of task is built upon in TBS (see 2.2). Throughout the literature, tasks are defined as being meaning-driven and bearing a relationship to real-world communication (i.e. the exchange of information, problem-solving, or making a collective judgment) that occurs in outside of the classroom (Skehan 1996b: 38). As Van den Branden and Van Avermeant (1995) write, "people not only learn language in order to make functional use of it, but also by making functional use of it” (cited in Van den Branden 2006: 6).

\subsection{Learning Theory: The Acquisition/Learning Distinction}

In the early 1980s Krashen (1982) developed a controversial hypothesis in regard to second language acquisition. He argued that there are distinct mental processes operating in L2 learning: conscious learning and subconscious acquisition (cited Nunan 1999: 43). As per this hypothesis, acquisition is an "unconscious process that involves the naturalistic development of language proficiency through understanding language and through language for meaningful communication” (Richards \& Rodgers 2001: 181). In other words, rules are acquired subconsciously through meaningful communication. In contrast, learning refers to the conscious rules about language that are developed through formal instruction. This process focuses on grammatical rules, "enabling the learner to memorize rules and to identify instances of rule violation” (Nunan 1999: 43). According to this theory, learning does not lead to acquisition.

Though highly controversial, the influence this distinction has had on TBS and TBLT is evident. TBS uses tasks as its primary unit of design as opposed to linguistic elements and does not endorse formal language instruction (as described above) as it is thought that form-focused teaching will produce language display instead of meaning exchange (Willis \& Willis 2007: 113). However, this is not to say there is no place for a linguistic or form focus within the framework. In fact, often built into the task sequence both implicitly and explicitly are opportunities for a focus on form to occur which aids in preventing fossilization as well as promoting language development and acquisition (Willis 1996: 60). 


\subsection{Learning Theory: Input/Output}

In addition to his Acquisition/Learning Hypothesis, Krashen developed another theory, which has influenced TBS. His theory of Comprehensible Input claims that language acquisition occurs through comprehension. More specifically, acquisition takes place when learners understand a message containing language that is one step ahead of their current level of competence, referred to as I +1 (Krashen and Tyrell 1983: 32; cited in Richards \& Rogers 2001: 182). In other words, through rich and varied I +1 input, learners' language systems will automatically develop without language-focused instruction (Skehan 1996b: 19).

However, others have argued that input alone is not sufficient for adequate language development. Swain (1985) claims that opportunities for productive language use are critical for full language development (cited in Richards \& Rodgers 2001: 228). In other words, attention to output is a key process in language learning as it affords learners opportunities to recognize gaps in their knowledge and ability as well as to test out their hypotheses about the language (Robinson 2011: 11). Both Input and Output theories have influenced the rationale for TBS and the utilization of tasks within this method as vehicles that "facilitate meaningful interaction and offer the learner ample opportunity to process meaningful input and produce meaningful output in order to reach relevant and obtainable goals” (Van den Branden 2006: 8).

\subsection{Learning Theory: Long's Interactional Hypothesis}

Another proponent for the importance of output in L2 acquisition was Long (1983, 1989) who argued that the interaction of learners in task work provides a way in which input can be made comprehensible in addition to offering opportunities for the negotiation of meaning to occur through attending to problematic forms in the input and output that transpire during task work (cited in Robinson 2011: 11). This is referred to as the negotiation of meaning which "concerns the way learners encounter communication difficulties while completing tasks, and how they do something about those difficulties (Skehan 2003: 3). According to the theory, the interactional adjustments learners make to address such difficulties leads to conversational adjustments and feedback which occur when "meaning is problematic, and when the learner is thought to be most receptive" (Pica 1994, cited in Skehan 2003: 3) a critical element to L2 acquisition (Bygate 1999: 36). Interaction and meaning negotiation have gone on to influence TBS in its utilization of pair and group work for task completion (Bruton 2002) in addition to its integration of a Focus-on-Form-a development of Long's negotiation of meaning (Long \& Robinson 1998, cited in Skehan 2003: 2)—into the task cycle as a vehicle for promoting language development.

\section{TBS: Strengths}

Having identified theories, which have influenced TBS, this portion of the paper will now consider strengths of TBS. 


\subsection{The Authenticity Factor}

As Long and Crookes point out, a major problem with synthetic or Type A syllabuses is the stilted and artificial language they produce because "they are written to conform to a set of linguistic specifications... and so do not reflect how people speak or write (much less learn) the language concerned (1992: 30). The strength of TBS is that it calls for the use of authentic materials in the classroom in order to provide the rich and varied input beneficial for L2 acquisition (see 3.4). These materials include professionally made recordings for film, video or $\mathrm{TV}$, published or unpublished written material as well as a wide range of text types available on the Internet. As Willis points out, "Extracts from these sources can be termed 'authentic' because they have not been produced with a specific language-teaching purpose in mind” (1996b: 69) but rather to communicate, inform and/or entertain.

The following are some advantages claimed for authentic materials as cited by Richards (Phillips and Shettlesworth 1978; Clarke 1989; Peacock 1997; cited in Richards 2001: 252):

- They positively effect learner motivation. Authentic materials are intrinsically more interesting and motivating than created materials (i.e. textbooks) and relate more closely to the interests of many language learners.

- They provide authentic cultural information. Materials can be selected to illustrate many aspects of L2 culture including practices, beliefs and both linguistic and non-linguistic behavior.

- They provide exposure to real language. As stated above, authentic materials are produced to communicate, inform and/or entertain and are therefore representative of natural language use. Learners are thus exposed to target language items in the kinds of contexts where they naturally occur (Nunan 1999: 27).

- They relate more closely to learner needs. Authentic materials bridge the gap between the classroom and real-world tasks, providing a link between educational content and learner needs in the real world.

The advantages of using authentic materials are evident as it exposes learners to genuine communication drawn from a variety of contexts. By using these materials in TBS, teachers can better equip their learners to successfully cope with genuine communication encountered outside the classroom (Nunan 1999: 80), thus empowering them to manage real-world L2 interactions.

\subsection{Nonlinguistic Focus}

What differentiates a task from an exercise is that a task has a nonlinguistic outcome while an exercise has a linguistic outcome (Nunan 1999: 25). This nonlinguistic focus is one of the greatest strengths of TBS as it shifts organizational focus from one of formal language knowledge demonstrated through language display to that of language use realized through meaningful communication exchanges. This point is further emphasized as assessment of task 
performance is based on outcome achieved via the language rather than linguistic display (see Skehan 1996b and section 2.2). The task-based syllabus, then, invites learners to learn language not only to make functional use of it, but by also by making functional use of it (Van den Branden 2006: 6). As Van den Branden goes on to note, "tasks invite the learner to act primarily as a language user, and not as a language learner" (2006: 8-9). In this view, the task-based syllabus sees language as a means to an end rather than the end itself thus helping to increase learner motivation as well as to promote $\mathrm{L} 2$ acquisition.

\subsection{Reflective of SLA Research}

TBS takes into account the cognitive processes necessary for L2 acquisition to take place (Prabhu 1987; Ellis 1985; Long \& Crookes 1992; Skehan 1996a, 1996b; Willis 1996a, 1996b, 2007). It reflects a greater understanding of the language learning process and recognizes that it is a complex notion where "the elements of the target language do not simply slot into place in a predictable order” (Skehan 1996a: 19). In response to this, TBS cultivates activities that provide learners with comprehensible input, meaningful communicative interaction, authentic materials and motivation as well as a focus on form in order to foster L2 acquisition. As Van den Branden aptly surmises, TBS acknowledges that:

[U]sing language is a means to an end: by understanding language input and by producing language output, i.e. by interacting with other people in real-life situations through the use of language, the goals that the learner has in mind can be (better) achieved. (2006: 4)

Thus, TBS links SLA theories to methodology so that learners, and the ways in which they learn, are at the center of pedagogic practices in the classroom

\section{TBS: Weaknesses}

Though the task-based syllabus's strengths are evident (see section 4) complications within the framework do exist. Van Avermaet and Gysen (2006: 29) identify three interrelated problems that typically arise in TBS design: specification, complexity and extrapolation. In this section the author will address specification, complexity in addition to assessment as representing areas of weakness within TBS.

\subsection{Specification}

The problem of specificity refers to the result of deriving tasks from the language situations identified in the needs analysis. This practice has the potential to result in endless lists of target tasks, which teachers may perceive as unattainable (Van Avermaet \& Gysen 2006: 29). In a similar vein, Long and Crookes (1992) cited the problem of finiteness as a potential stumbling block in TBS design. Finiteness, like specification, refers to the parameters that distinguish one task type from another. As Long and Crookes inquire, "How many tasks and task types are there? Where does one task end and the next begin?” (1992: 46). In addition to this, the distinction of what constitutes a task and what does not is often vague. As Bruton points out, "there are many instances of communication which cannot be termed as tasks, 
talking to your best friend, for instance” (Bruton 2002: 285). The specificity and finiteness of task is therefore a weakness within TBS, as the delineation of tasks remains "riddled with complications” (Bruton 2002: 285).

\subsection{Complexity}

Included in the issue of task complexity is that of task difficulty as both terms "are used interchangeably and the scope of potential influences on them is argued to be very wide" (Robinson 2001: 29). This leads to further complications for the grading and sequencing of tasks, which use both complexity and difficulty as influential factors in sequencing decisions. Skehan (1996a: 23) identifies the following three factors, which contribute to the difficulty of task:

- Code complexity: the syntactic and lexical difficulty of language input.

- Cognitive complexity: the processing demands of tasks and the availability of relevant schematic knowledge.

- Communicative stress: the result of differentials in time pressure, modality, scale, stakes or control.

Robinson (2001), on the other hand, cites 'complexity' and 'difficulty' as having two distinct influences on task performance and thus task sequencing. He suggests task sequencing decision be based on the following criteria:

- Task complexity: the result of the attentional, memory, reasoning and other information processing demands imposed by the structure of the task on the language learner (2001: 29).

- Task difficulty: the learner factors which may make a task more or less difficult, i.e. differentials between learners in their available attentional, memory and reasoning resource pools (2001: 31).

- Task conditions: the interactive demands of the task, i.e. participation factors such as direction of information flow and communicative goals and participant factors including gender, familiarity and relative status (2001: 32).

Though both schemes prove useful in making task-sequencing decisions, "a valid, user-friendly sequencing criteria remains one of the oldest unsolved problems in language teaching of all kinds” (Long \& Crookes 1992: 46) and thus a weakness in TBS.

\subsection{Assessment}

As Van den Branden (2006: 12) notes, "the field of task-based testing is still very young” and until more research is done in this area it can be interpreted as a weakness of TBS. Challenges of task-based assessment include: 1) determining rating scales and performance criteria, 2) selecting test tasks that allow for valid and reliable test scores 3) extrapolating from test performance to real-world performance across tasks, 4) and increased cost and 
logistical problems (Bachman 2002; McNamara 1995; Messick 1994; Norris et al. 1998; cited in Van den Branded 2006: 12). For now, without concrete parameters for task-based assessment, TBS can be seen as lacking in terms of accountability, preventing it from becoming accepted by certain educational authorities or institutions.

\section{Ideal Setting for TBS: EFL Classroom with Task-Based Assessment}

It is almost axiomatic to say that the best suited setting for TBS is an English for Specific Purposes or Survival English course in an ESL setting (Sheen 1994: 145) as in both situations, learners will have clear and identifiable needs and opportunities to put their L2 to immediate use in real-world communication. However, based on her teaching experiences at Sookmyung Women's University in Korea (2010-2011), the writer would argue that the best-suited situation for TBS is an EFL classroom supported by institutionalized, task-based assessment.

EFL contexts are where TBS could be most beneficial to students who have minimal opportunities to use the L2 outside of the classroom and thus see little purpose to learning the L2. Through its emphasis on meaning and utilization of authentic materials, TBS offers learners an enriched experience of L2 learning in which immediate use of the L2 produces tangible results giving purpose and meaning to the L2 learning process. However, the author would propose that in order for TBS to be most effective in an EFL context the following criteria are essential:

- Smaller class sizes: As Ellis, "TBLT is not easily implemented in large classes - a structural feature of many educational contexts” (2009: 242).

- Task-based assessment: Though many difficulties exist in regard to task-based assessment (see 5.3), TBS "calls for the use of performance-based testing” (Ellis 2009: 242) which is claimed to have many benefits "including positive backwash effects on education and the potential to offer more accurate assessments of students' abilities to use language in real-world situations” (Brown et al. 2002; Norris et al. 1998; cited in Van den Branden 2006: 11).

At Sookmyung Women's University, General English class sizes were comprised of no more than 17 students making the implementation of classroom tasks effective and manageable. Additonally, all students taking General English courses were required to take an institutionalized task-based final exam, which was also necessary to pass in order to graduate. Having this task-based assessment in place helped to rectify some of the problems associated in TBS implementation in EFL contexts (Sheen 1994). For example, despite being a General English course, a valid needs analysis was easy to obtain as the target tasks identified by the students related directly to the tasks on the exam thus making the selection of pedagogic tasks a virtually straightforward process. 


\section{Arguments in Favor of TBS}

Despite the weaknesses outlined in the previous section, the author would propose the following arguments in favor of choosing TBS.

\subsection{Meets Conditions for Learning}

Though learning styles of students are as individual and varied as the students themselves, SLA research findings imply that there are four key conditions to be met for effective learning to take place. Willis (1996a: 59-60) outlines them as the exposure, use of language, motivation and a focus on language. A task-based syllabus successfully meets these four conditions in the following ways:

- Exposure: TBS can be designed to expose students to a variety of input ranging from teacher talk and learner-learner interaction to real language use from authentic materials (see 4.1). As Willis (1996a: 59) notes, "This input is not confined to sentence level examples, but consists of real, often spontaneous, language use” necessary for the noticing and processing of language features which is essential for acquisition to take place.

- Use of Language: The very nature of the task, and thus TBS, is the use of language to achieve task outcomes. Successful task completion hinges on meaningful communication exchanges where learners say what they want to say, take turns, control the interaction and interact spontaneously to realize task goals (Willis 1996a: 59).

- Motivation: As Willis (1996b: 11) states, "Success and satisfaction are key factors in sustaining motivation”. As goal-oriented activities, tasks provide students opportunities to achieve both as they employ the L2 to obtain tangible outcomes. Task completion further propels student motivation since students who feel they have achieved something worthwhile are more likely to participate the following time (Willis 1996b: 11). Completing tasks is the key component of TBS, thus making it an inherently motivating syllabus type.

- Focus on Form: In the task framework, there is a natural focus on form as students negotiate meaning during interaction and prepare to make public the results of their task-work to the class. In addition, the task cycle as proposed by Willis (1996b: 60), makes room for opportunities to focus exclusively on form as they analyze and practice the features of language that naturally occurred during task work through consciousness-raising activities (Willis 1996b: 16; Willis 1996a: 63).

\subsection{Facilitates Learner Empowerment}

As Good Language Learner (GLL) research has demonstrated, effective learners are those that are aware of the processes underlying their own learning and who successfully use appropriate strategies to reach their learning objectives (see Rubin 1975; Naiman et al. 1978; 
Chamat \& Kuper 1989; Oxford 1990; Nunan 1999; Chamot 2005; Tseng et al. 2006). TBS is an ideal vehicle to promote language learning strategy awareness and use amongst learners as Nunan asserts, "Underlying every task that one introduces to the classroom is a learning strategy of one kind or another” (1999: 182). In TBS, learners take the central role as each task they approach involves a process of decision-making, planning and implementation of strategies (Bialystock 1985). By highlighting these strategies and their centrality to task performance, students become more aware of - and involved in - their L2 learning process and consequently more empowered as they are better able to make effective choices in terms of learning tasks and strategies to achieve task goals (Nunan 1999: 193).

\section{Conclusion}

Having examined the task-based syllabus and analyzed it in terms of theoretical influences, strengths and weaknesses, it is evident that TBS holds much promise for the realm of language learning and teaching. Through its utilization of tasks as vehicles for comprehensible input, meaning driven interaction, motivation and a focus on form aimed at interlanguage development and L2 acquisition, TBS is an ideal choice for EFL teaching contexts that are supported by small class sizes and institutionalized task-based exams. Though more research is necessary in order to resolve issues regarding task specific, task complexity and task-based assessment, TBS still remains the most encouraging syllabus type as a means for promoting L2 acquisition and facilitating learner empowerment.

\section{Acknowledgment}

This work was supported by the Hankuk University of Foreign Studies Research Fund of 2014.

\section{References}

Bruton, A.B. (2002). From tasking purposes to purposing tasks. ELT Journal, 56(3), 280-288. http://dx.doi.org/10.1093/elt/56.3.280

Bygate, M. (1999). Task as context for the framing, reframing and unframing of language. System, 27(33/48), 33-48. http://dx.doi.org/10.1016/S0346-251X(98)00048-7

Ellis, R. (1985). An Introduction to Second Language Acquisition. Oxford: Oxford University Press.

Ellis, R. (2009). Task-based language teaching: sorting out the misunderstandings. International Journal of Applied Linguistics, 19(3), 221-246. http://dx.doi.org/10.1111/j.1473-4192.2009.00231.x

Lewis, M. (2002). Implications of a lexical view of language. In Willis, J. and Willis, D. (1996a) (eds) Challenge and Change in Language Teaching. Oxford: Heinemann, 
10-16.

Littlewood, W. (2004). The task-based approach: some questions and suggestions. ELT Journal, 58(4), 319-326. http://dx.doi.org/10.1093/elt/58.4.319

Long M.H., \& Crookes, G. (1992). Three Approaches to Task-Based Syllabus Design. TESOL Quarterly, 26(1), 27-56. http://dx.doi.org/10.2307/3587368

McGrath, I. (2002). Materials Evaluation and Design for Language Teaching. Edinburgh: Edinburgh University Press.

Nunan, D. (1987). Communicative language teaching: Making it work. ELT Journal, 41(2), 136-145. http://dx.doi.org/10.1093/elt/41.2.136

Nunan, D. (1999). Second Language Teaching \& Learning. Boston: Heinle \& Heinle Publishers.

Rahimpour, M. (2010). Current trends on syllabus design in foreign language instruction. Social and Behavioral Sciences, 2, 1660-1664.

Richards, J.C., \& Rodgers T.S. (2001). Approaches and Methods in Language Teaching (2 ${ }^{\text {nd }}$ ed.). Cambridge: Cambridge University Press. http://dx.doi.org/10.1017/CBO9780511667305

Richards, J.C. (2001). Curriculum Development in Language Teaching(7th ed.). Cambridge: Cambridge University Press. http://dx.doi.org/10.1017/CBO9780511667220

Richards, J.C. (2006). Communicative Language Teaching Today. Cambridge: Cambridge University Press.

Robinson, P. (2001). Task complexity, task difficulty, and task production: Exploring interactions in a componential framework. Applied Linguistics, 22(1), 27-57. http://dx.doi.org/10.1093/applin/22.1.27

Robinson, P. (2011). Task-Based Language Learning: A review of Issues. Language Learning, 61(1), 1-36. http://dx.doi.org/10.1111/j.1467-9922.2011.00641.x

Sheen, R. (1994). A Critical Analysis of the Advocacy of the Task-Based Syllabus. TESOL Quarterly, 28(1), 127-151. http://dx.doi.org/10.2307/3587202

Skehan, P. (1996a). Second language acquisition research and task-based instruction. In Willis, J. and Willis, D. (eds) Challenge and Change in Language Teaching. Oxford: Heinemann 17-30.

Skehan, P. (1996b). A framework for the implementation of task-based instruction. Applied Linguistics, 17(1), 38-62. http://dx.doi.org/10.1093/applin/17.1.38

Skehan, P. (2002). A non-marginal role for tasks. ELT Journal, 56(3), 289-295. http://dx.doi.org/10.1093/elt/56.3.289

Skehan, P. (2003). Task-based instruction. Language Teaching, 36, 1-14. 
http://dx.doi.org/10.1017/S026144480200188X

Skehan, P., \& Foster, P. (1999). The influence of source of planning and focus of planning on task-based performance. Language Teaching Research, 3(3), 215-247. http://dx.doi.org/10.1177/136216889900300303

Valdman, A. (2006). Communicative Use of Language and Syllabus Design. Foreign Language Annals, 11(5), 567-580. http://dx.doi.org/10.1111/j.1944-9720.1978.tb00728.x

Van Avarmaet, P., \& Gysen, S. (2006). From needs to tasks: language learning needs in a task-based approach. In Van den Branden, K. (ed), Task-Based Language Education: from theory to practice. Cambridge: Cambridge University Press, 17-46. http://dx.doi.org/10.1017/CBO9780511667282.003

Van den Branden, K. (2006). Introduction: task-based language teaching in a nutshell. In Van den Branden, K. (ed), Task-Based Language Education: from theory to practice. Cambridge: Cambridge University 1-16. http://dx.doi.org/10.1017/CBO9780511667282.002

Van den Branden, K. (2006). Task-Based Language Education: from theory to practice. Cambridge: Cambridge University Press. http://dx.doi.org/10.1017/CBO9780511667282

White, R.V. (1988). The ELT Curriculum. Oxford: Blackwell.

Willis, D. (1996). Accuracy, fluency and conformity. In Willis, J. and Willis, D. (1996a) (eds), Challenge and Change in Language Teaching. Oxford: Heinemann, 44-51.

Willis, J. (1996a). A flexible framework for task-based learning. In Willis, J. and Willis, D. (1996a) (eds), Challenge and Change in Language Teaching. Oxford: Heinemann, 52-62.

Willis, J. (1996b). A Framework for Task-based Learning. Harlow: Longman.

Willis, J., \& Willis, D. (1996a). (eds) Challenge and Change in Language Teaching. Oxford: Heinemann.

Willis, J., \& Willis, D. (2007). Doing Task-Based Teaching. Oxford: Oxford University Press.

\section{Copyright Disclaimer}

Copyright reserved by the author(s).

This article is an open-access article distributed under the terms and conditions of the Creative Commons Attribution license (http://creativecommons.org/licenses/by/3.0/). 